(1) O Observatori de

Bioètica i Dret

ISSN: $1886-5887$

\section{Revista de Bioética y Derecho}

Publicación del Máster en Bioética y Derecho nww.bioeticayderecho.ub.es

ARTíCULO

\title{
A macrobioética e os direitos humanos: um caminho para o humanismo dialético
}

\author{
The macro-bioethics and human rights: way for dialectical \\ humanism
}

\author{
Roberto Galvão Faleiros JÚNIOR * \\ Paulo César Corrêa Borges
}

Fecha de recepción: 1 de diciembre 2011

Fecha de aceptación: 7 de febrero 2012

\footnotetext{
* Roberto Galvão Faleiros Júnior. Mestrando em Direito pela Faculdade de Ciências Humanas e Sociais da UNESP - Universidade Estadual Paulista - Campus de Franca - Estado de São Paulo/Brasil. Bolsista PROPG/CAPES. Integrante do NETPDH (Núcleo de Estudos da Tutela Penal e Educação em Direitos Humanos) e do Observatório de Bioética e Direito, ambos da UNESP-Franca. robfaleiros@yahoo.com.br

* Paulo César Corrêa Borges. Prof. Dr. Coordenador da Pós-Graduação em Direito da Faculdade de Ciências Humanas e Sociais da UNESP - Universidade Estadual Paulista - Campus de Franca e do NETPDH (Núcleo de Estudos da Tutela Penal e Educação em Direitos Humanos) - Estado de São Paulo/Brasil. Promotor de Justiça em Franca/SP. pauloborges@franca.unesp.br
} 


\section{Índice}
I. Introdução
II. A crise e novos paradigmas científicos
III. Macrobioética e os direitos humanos
IV. Considerações finais
V. Referências bibliográficas

\section{Resumo}

Com o desenvolvimento da sociedade humana, contemporaneamente, produziram-se inúmeros avanços, mas também alguns aspectos catastróficos. Este fenômeno contraditório induz o ser humano a uma absolutização de posturas e uma busca permanente por resultados, eficiência e acúmulos. Assim, a atual forma de progresso tecnológico e econômico, na sustentação de seus objetivos e supervalorização dos fins, inexoravelmente fragiliza a bioética. Com a formação histórica dos direitos humanos é demonstrada a necessidade de efetiva proteção do meio ambiente, identificando-se alguns pontos de tensão que aparecem quando são intensificadas as degradações humanas e as carências de recursos naturais. A importância de ser recorrer ao estudo da bioética se evidencia com a crise do paradigma científico dominante e as incongruências das formulações da sociedade globalizada. Esta constatação crítica é necessária para, através da busca da libertação humana, edificar-se um humanismo dialético.

Palavras-chave: Direitos Humanos, macrobioética, humanismo dialético.

\section{Abstract}

With the development of human society, contemporaneously, producing numerous advances, but also some catastrophic. This contradictory phenomenon induces human beings to an absolutism of postures and a permanent quest for results, efficiency and accumulation. Thus, the current form of technological and economic progress, in support of its objectives and purposes of overvaluation, inexorably weakens bioethics. With the historical development of human rights is demonstrated the need for effective protection of the environment, identifying some points of tension that arise when the fades are intensified the shortage of human and natural resources. The importance of resorting to the study of bioethics is evident from the crisis of the dominant scientific paradigm of the formulations and inconsistencies of a globalized society. This critical finding is needed, through the pursuit of human liberation, build up a dialectical humanism.

Key words: Human Rights, macro-bioethics, dialectical humanism. 


\section{Introdução}

O desenvolvimento da sociedade humana comportou inúmeros avanços e retrocessos. Podemos visualizar, especificamente, diversos campos que objetivaram progressos para o bem estar da vida humana concreta. De outro lado, percebe-se a desconsideração de pontos importantes para o pleno desenvolvimento das potencialidades das vivências humanas.

As necessidades biológicas direcionaram o esforço civilizatório para uma permanente tentativa de acúmulo de energia e otimização do tempo, numa potencialização do trabalho com todas as nuances emergenciais. De forma amplificada, uma busca constante por eficiências, produção de energia e concentração de capital, influenciou diversos aspectos no mundo social, na saúde, na política, etc.

Com o progresso tecnológico e científico é expandida a criação de elementos que permitem uma vida mais cômoda, com facilidades para o transporte, prolongamento da vida com 0 avanço da medicina, acarretando em profícuas mudanças na vida do ser humano.

Em diversos aspectos da vida social surgiram constantes tentativas de formulação de novos métodos e processos com o claro objetivo da máxima eficácia do aproveitamento energético e econômico, dentro de uma racionalidade instrumental.

A abordagem da civilização a partir dessa absolutização de instrumentos e racionalidades acaba consumindo infindáveis recursos naturais, sobretudo em busca de energia para a sustentação deste processo, o que ao invés de edificar riquezas e independências, gera pobreza, concentração e subordinação.

O desenvolvimento da racionalidade técnica-instrumental e sua pretensa necessidade levam a diversas discrepâncias na organização dos poderes instituídos, gerando possíveis transformaç̧ões políticas e sociais importantes.

Esse processo, nomeado por planetarização ou globalização é "acompanhada de mercados livres, atualmente tão em voga, trouxe consigo uma dramática acentuação das desigualdades econômicas e sociais no interior das nações e entre elas"1.

Esta expansão desmedida leva tanto aos dilaceramentos culturais irrevogáveis, acarretando numa sobreposição de valores civilizatórios, formando perigosos desequilíbrios sócio-culturais, como a destruição do meio ambiente, atingindo milhares de seres humanos. Os principais artífices deste processo são o comércio e a guerra. Paradoxalmente essa desagregação acaba não formando novas organizações sociais e, em nome de um pretenso desenvolvimento econômico, subordinam-se povos e países numa servidão irracional.

Ocorre a coisificação do homem, da natureza e a supervalorização das instrumentalidades, dos meios, do econômico.

\footnotetext{
1 HOBSBAWM, Eric. Globalização, Democracia e Terrorismo. Trad. José Viegas. São Paulo: Companhia das
} Letras, 2007., p. 11. 
Dentro do estudo do Direito, existem inúmeras teorias que corroboram estas perspectivas aniquiladoras e procuram explicar o fenômeno jurídico utilizando-se de diversas metodologias, recortes, posturas, discursos, em sua maioria de maneira insuficiente e reducionista, pois sustentadas ora em entes metafísicos, ora, apenas, em leis ou normas estipuladas. Assim, de maneira didática podem ser condensadas em dois modelos: subordinação ao Direito Natural e o positivismo jurídico básico². Qualquer que seja o modelo adotado para a compreensão jurídica destes fenômenos sociais estará dentro "dos paradigmas do legalismo liberal."3

Portanto, para um estudo contextualizado e sócio-histórico, necessário retratar as crises paradigmáticas e a fragilização dos direitos humanos, em especial da macrobiética.

\section{A crise e novos paradigmas científicos}

A formulação dos paradigmas liberais científicos, e por conseqüência do direito, foi delineada após as revoluções liberais do século XVIII, da revolução industrial e do lluminismo. Neste cenário, numa tentativa de superar a estagnação da Idade Média, a civilização ocidental produziu a ciência moderna com seus postulados e formulações, fundada na busca permanente da eficiência a qualquer custo.

As evoluções epistemológicas, sociológicas e metodológicas foram evidentes. As sociedades ocidentais se desenvolveram de forma avassaladora e inúmeras vidas foram salvas. A medicina, a biologia, a astronomia permitiram que os sujeitos recebessem inúmeros benefícios e se colocassem como centralidade nas preocupações científicas relegando os dogmas calcados na existência divina.

Ocorre que como parte da formação da sociedade contemporânea, alguns desvios e exageros levaram a novos confrontos teóricos e filosóficos. Estas perspectivas basilares edificaram no mundo moderno os cânones do tecnicismo e a prevalência do paradigma dominante da ciência moderna. Em muitos momentos, os métodos se sobrepuseram aos sujeitos e alguns descaminhos foram maléficos para o ser humano.

No direito e na macrobioética, estes paradigmas dominantes ainda são hegemônicos e constantemente exteriorizados, formados pela norma como objeto exclusivo do estudo jurídico-político, o método lógico-formal, a ideologia liberal e a filosofia racional-analítica ${ }^{4}$.

Com o limiar do Século XX, uma nova tentativa de compreensão desta sociedade, com respaldo em outras bases filosóficas e científicas se inicia. Ocorre a tentativa de formulação de um paradigma emergente fundado não apenas na instrumentalidade técnica, na racionalidade científica, mas calcada na concretização da vida humana. É neste sentido que Boaventura de Sousa Santos formula:

\footnotetext{
${ }^{2}$ LYRA FILHO, Roberto. Razões de defesa do direito. Brasília: Editora Obreira, 1981, p. 16-17.

3 MACHADO, Antônio Alberto. "A teoria do Direito e os paradigmas positivistas." In: BORGES, Paulo César Corrêa (Org.). Marcadores sociais da diferença e repressão penal. São Paulo: Cultura Acadêmica Editora, 2011, p. 27.

4 MACHADO, Antônio Alberto. "A teoria do Direito e os paradigmas positivistas." In: BORGES, Paulo César Corrêa (Org.). Marcadores sociais da diferença e repressão penal. São Paulo: Cultura Acadêmica Editora, 2011, p. 27-28.
} 
Sendo uma revolução científica que ocorre numa sociedade ela própria revolucionada pela ciência, o paradigma a emergir dela não pode ser apenas um paradigma científico lo paradigma de um conhecimento prudente), tem de ser também um paradigma social (o paradigma de uma vida decente) ${ }^{5}$.

Este peculiar momento de crise, de edificação de novos paradigmas científicos, tem profundos reflexos na sociedade globalizada, dentro da ciência jurídica e do estudo da macrobiética. Algumas formulações absolutas são contestadas e novas perspectivas são necessárias para a proteção e defesa dos direitos fundamentais já fragilizados.

A desconfiguração provocada pela objetivação dos sujeitos acabou violando direitos fundamentais historicamente conquistados. A privacidade, o patrimônio genético e o meio ambiente, correm risco em decorrência do desenfreado avanço técnico-econômico. Também por isso que se deve superar a visão dicotômica do fenômeno social, edificando-se uma nova forma de ser da técnica e do objeto-sujeito científico. Neste viés, esclarece:

O conhecimento do paradigma emergente tende assim a ser um conhecimento não dualista, um conhecimento que se funda na superação das distinções tão familiares e óbvias que até há pouco considerávamos insubstituíveis, tais como natureza/cultura, natural/artificial, vivo/inanimado, ente/matéria, observador/observado, subjetivo/objetivo, coletivo/individual, animal/pessoa. Este relativo colapso das distinções dicotômicas repercute-se nas disciplinas cientificas que sobre elas se fundaram. Aliás, sempre houve ciências que se reconheceram mal nestas distinções e tanto que se tiveram de fraturar internamente para se thes adequarem minimamente. Refiro-me à antropologia, à geografia e também à psicologia. Condensaram-se nelas privilegiadamente as contradições da separação ciências naturais/ciências sociais. Daí que, num período de transição entre paradigmas, seja particularmente importante, do ponto de vista epistemológico, observar o que se passa nessas ciências. ${ }^{6}$

Portanto, esta transição paradigmática é de suma importância para o fortalecimento dos direitos humanos nessa globalização fragmentada, com especial atenção para a formulação e aplicação de preceitos éticos e políticos na defesa do meio ambiente e na concretização destes direitos.

\section{Macrobioética e os direitos humanos}

Entendida as formulações da sociedade contemporânea e a necessidade de mudança paradigmática da ciência moderna, apresenta-se a necessidade de analisar a fragilização dos direitos humanos e em especial do meio ambiente.

Esta preocupação emerge-se no atual momento histórico em razão da própria característica dos direitos humanos. As necessidades humanas são realçadas e identificadas com o desenrolar histórico e a preocupação com o meio ambiente é enfatizada com a crescente degradação desencadeada pela sociedade. Esta percepção é peculiarmente retratada por Norberto Bobbio ao identifica que:

\footnotetext{
${ }^{5}$ SANTOS, Boaventura de Sousa. Um discurso sobre as Ciências. 7a ed. Porto: Afrontamento, 1995, p. 37.

${ }^{6}$ SANTOS, Boaventura de Sousa. Um discurso sobre as Ciências. 7a ed. Porto: Afrontamento, 1995, p. 39-40.
} 
Também os direitos do homem são direitos históricos, que emergem gradualmente das lutas que o homem trava por sua própria emancipação e das transformações das condições de vida que essas lutas produzem. A expressão "direitos do homem" que é certamente enfática - ainda que oportunamente enfática -, pode provocar equívocos, já que faz pensar na existência de direitos que pertencem a um homem abstrato e, como tal, subtraído ao fluxo da história, a um homem essencial e eterno, de cuja contemplação deveríamos o conhecimento infalível dos seus direitos e deveres. ${ }^{7}$

A percepção da historicidade dos direitos humanos permite uma compreensão processual das questões que envolvem a macrobioética. Contudo, os sujeitos e os grupos humanos também fazem parte desse processo histórico. Nesse sentido, pode-se e deve-se ampliar essa concepção através de "una lectura sociohistórica de derechos humanos con énfasis en el universo de opciones y valores, abierto y procesual, de la producción de mundo a la que se ha consignado bajo el concepto de 'sociedades civiles emergentes'."8

Deste modo, as sociedades civis emergentes no final do Século XX e início do XXI demandaram o reconhecimento, positivação e expansão de seus valores e interesses condensados na denominação de macrobioética.

Apenas nesse momento que, o desmatamento de florestas, a poluição de rios e lagos e a impermeabilização do solo são considerados problemas gerados pelo próprio desenvolvimento humano e avivados quando tensionados pelos indivíduos e pelas sociedades civis emergentes.

Os anseios e reivindicações pelo respeito do meio ambiente nestas situações de devastações são possibilitados, também, pelo entendimento abrangente que direitos humanos "têm mais a ver com processos de lutas para abrir e consolidar espaços de liberdade e dignidade humana", pois, em dada medida, direcionados "contra os excessos de qualquer tipo de poder que impedem aos seres humanos constituírem-se como sujeitos."

Decisivas, portanto, as peculiaridades das questões que envolvem a macrobioética, pois permitem ampliar situações de liberdade e respeito da dignidade humana, potencializando, ainda, o empoderamento concreto da vida dos sujeitos.

Assim, a exploração ambiental que anteriormente não era problematizada e regulamentada, passa a ser encarada como degradante a partir do momento em que novas técnicas e poderes são criados e alterações no meio ambiente e no clima começam a gerar problemas para a humanidade. Da mesma forma, sucede-se com outros recursos naturais e energéticos. É, portanto, neste momento que as preocupações se avolumam:

Com desenvolvimento da técnica, transformações das condições econômicas e sociais, ampliação dos conhecimentos intensificação dos meios de comunicação - produzirão mudanças - na organização da vida humana e das relações sociais - ocasiões para novas demandas de liberdade e poderes ${ }^{10}$.

\footnotetext{
7 BOBBIO, Norberto. A Era dos direitos. Rio de Janeiro: Campus, 1992, p. 32.

8 GALLARDO, Helio. Teoría Crítica: matriz y posibilidad de derechos humanos. Murcia: Gráficas F. Gómez. Editado por David Sánchez Rubio, 2008, p. 312.

${ }^{9}$ RUBIO, David Sánchez. Fazendo e desfazendo Direitos Humanos. Santa Cruz do Sul: EDUNISC, 2010, p. 17.

${ }^{10}$ BOBBIO, Norberto. A Era dos direitos. Rio de Janeiro: Campus, 1992, p. 33.
} 
Dentro deste cenário ressaltam-se e questionam-se as condicionantes deste progresso econômicos, identificando sérios riscos para a liberdade humana. Em razão destas constatações surge a preocupação com a ética, o meio ambiente e a dignidade do ser humano. Estes fatores geram para alguns doutrinadores a denominada bioética.

Esta abordagem, como dito, em função da historicidade dos direitos humanos, foi evidenciada no final do século passado, principalmente com o aumento dos problemas ambientais. A incorporação e evolução de novas tecnologias clamam para o desenvolvimento de soluções e repostas para os problemas gerados por este próprio desenvolvimento. Assim, a compreensão e estudos sobre a bioética ampliam-se e incorporam-se novas questões:

A bioética seria, em sentido amplo, uma resposta da ética às novas situações oriundas da ciência no âmbito da saúde; ocupando-se não só dos problemas éticos, [...] como também dos decorrentes da degradação do meio ambiente, da destinação do equilíbrio ecológico e do uso de armas químicas ${ }^{11}$.

Dentro da denominada bioética, alguns estudiosos alargam a temática e tratam, também, da denominada "bioética das situações emergentes", que abrangeria a macrobioética. Este intuito é louvável, principalmente por tratar as questões ecológicas, a preservação da vida e do bem-estar do ser humano não apenas de forma instrumental, quantificável, mas a partir de uma preocupação ética, axiológica, filosófica.

Dentro desta ampliação, inúmeras práticas cotidianas são questionadas. Identificamos infindáveis tipos de poluição, a ruptura dos ciclos biológico dos animais, a produção de agrotóxicos, o esgotamento dos recursos naturais, a falta d'água e ainda a desertificação de solos agricultáveis.

Por conta desta racionalidade técnica, segundo a OIT (Organização Internacional do Trabalho) entre 1995 e os dias atuais no Brasil, aproximadamente 40.000 pessoas foram resgatadas de condições análogas ao trabalho escravo que --- conforme legislação brasileira --- ocorre quando alguém é submetido a trabalhos forçados, jornada exaustiva, condições degradantes de trabalho, ou, ainda, quando tem restringida sua locomoção em razão de dívida contraída com o empregador ou preposto. ${ }^{12}$

Os desmatamentos provocados na Amazônia atendem quase que exclusivamente ao anseio da eficiência dos plantadores de soja e criadores de gado. Os procedimentos utilizados para a colheita da cana, ou seja, a queimada da palha, e o corte manual efetuado pelos trabalhadores levam em contam apenas a produtividade, o aspecto econômico. Neste sentido, são inúmeros os responsáveis, ética e juridicamente, pela violação dos direitos humanos e do meio ambiente em razão da manutenção deste instrumental irracional.

Estas situações demonstram uma falência deste modelo cientificista, fundados na busca sem medida pela eficiência das atividades humanas. A civilização contemporânea prioriza sentidos e anseios que, em dadas instâncias, menosprezam os sujeitos e degrada o meio ambiente.

\footnotetext{
${ }^{11}$ DINIZ, Maria Helena. Estado atual do biodireito. 2.ed. São Paulo: Saraiva, 2002, p. 11-12.

12 Perfil dos principais atores envolvidos no trabalho escravo rural no Brasil / Organização Internacional do Trabalho. - Brasília: OIT, 2011. Disponível em:

http://www.oit.org.br/sites/default/files/topic/forced_labour/doc/perfil_completo_624.pdf. Acesso: 13 de Novembro de 2011.
} 
Além disso, os exemplos mencionados são um afronta à bioética, pois, demonstram um cotidiano desrespeito ao meio ambiente, à saúde e à dignidade humana. Neste viés:

Para tanto, a bioética precisa de um paradigma de referência antropológico-moral: o valor supremo da pessoa humana, de sua vida, dignidade e liberdade ou autonomia, dentro da linguagem dos direitos humanos e em busca de uma qualidade de vida digna, dando, portanto, prioridade ao ser humano e não às instituições voltadas à biotecnociência. A bioética não poderá preocupar-ser apenas com os caminhos para a solução dos problemas bioéticos; deverá levar à aquisição de hábitos éticos e de qualidade de caráter. ${ }^{13}$

Assim, as formulações da bioética e a revalorização da natureza são importantes instrumentos para o fortalecimento dos direitos humanos, do meio ambiente e do Estado Democrático de Direito. Neste entendimento, anuncia Maria Helena Diniz:

O Direito ao meio ambiente sadio e ecologicamente equilibrado é o direito à vida e à preservação de tudo o que for imprescindível para a boa qualidade, e somente poderá ser conquistada pela conformação das atividades socioeconômicas no sentido de que se deve respeitar a biodiversidade para evitar a degradação ambiental. Só a obediência ao principio da defesa do meio ambiente possibilitaria a concretização do direito ao meio ambiente ecologicamente equilibrado para as gerações presentes e futuras. A atual geração não tem o direito de destruir o meio ambiente, pois dele poderá retirar frutos $e$ produtos indispensáveis à sua sobrevivência, tendo o dever de protegê-lo e conservá-lo, para transmitit-lo à geração futura, fundamentando-se, portanto, no princípio da perpetuação das espécies. ${ }^{14}$

\section{Considerações finais}

Como mencionado, alguns efeitos do progresso humano estão acompanhados por questões trágicas que, em alguns momentos, são invisibilizados por diversos interesses. Ou seja, efeitos imprevisíveis, indesejáveis são correntes dentro deste processo. A civilização moderna é direcionada para uma busca incessante pela eficiência e suplanta e fragiliza os direitos humanos e o meio ambiente.

O homem se tornou objeto da racionalidade instrumental, da produtividade, da eficiência estritamente econômica, afastando-se de qualquer interação profunda e não hierarquizante com a natureza. Numa tentativa de contrapor esta triste constatação, buscando a concretização e respeito à dignidade humana e ao meio ambiente, recorre-se aos postulados da bioética.

Necessário, portanto, expandir e reconhecer a importância ao meio ambiente equilibrado, à vida e à dignidade humana, para permitir o exercício de todos os outros direitos ditos fundamentais.

A afirmação e eficácia de direitos metaindividuais, como o meio ambiente, irradiam fundamentos para o respeito e efervescência das outras categorias de direitos. A abordagem coletivizada da tutela do meio ambiente, com respaldo na bioética, permite um confronto com os fenômenos contemporâneos, denunciando suas nefastas produções de malefícios para a humanidade.

\footnotetext{
${ }^{13}$ DINIZ, Maria Helena. Estado atual do biodireito. 2.ed. São Paulo: Saraiva, 2002, p. 13.

${ }^{14}$ DINIZ, Maria Helena. Estado atual do biodireito. 2.ed. São Paulo: Saraiva, 2002, p. 614.
} 
A humanidade tem o direito a um meio ambiente límpido, seguro e equilibrado, bem como as futuras gerações também têm o direito de desfrutarem de um meio ambiente preservado com respeito à dignidade humana. De modo que, "Por outras palavras, o que busco é a refundamentação dos Direitos Humanos, conforme o processo concreto da humana libertação. Trata-se duma filosofia jurídica, a que se poderia dar o nome de humanismo dialético." ${ }^{15}$

Portanto, com a suplantação das finalidades instrumentais da civilização contemporânea e a mudança paradigmática da ciência moderna, com respaldo nas formulações da macrobioética, possibilitará uma concreta tutela dos direitos humanos e respeito ao meio ambiente, com a edificação de novos sujeitos.

\section{Referências bibliográficas}

- BOBBIO, Norberto. A Era dos direitos. Rio de Janeiro: Campus, 1992.

- DINIZ, Maria Helena. Estado atual do biodireito. 2.ed. São Paulo: Saraiva, 2002.

- GALLARDO, Helio. Teoría Crítica: matriz y posibilidad de derechos humanos. Murcia: Gráficas F. Gómez. Editado por David Sánchez Rubio, 2008.

- HOBSBAWM, Eric. Globalização, Democracia e Terrorismo. Trad. José Viegas. São Paulo: Companhia das Letras, 2007.

- LYRA FILHO, Roberto. "Desordem e processo: Um posfácio explicativo". In: LYRA, Deodoró Araujo (Org.). Desordem e processo: estudos sobre o Direito em homenagem a Roberto Lyra Filho, na ocasião do seu 60ํaniversário. Porto Alegre: Sergio Antonio Fabris Editor, 1986.

- LYRA FILHO, Roberto. Razões de defesa do direito. Brasília: Editora Obreira, 1981.

- MACHADO, Antônio Alberto. "A teoria do Direito e os paradigmas positivistas." In: BORGES, Paulo César Corrêa (Org.). Marcadores sociais da diferença e repressão penal. São Paulo: Cultura Acadêmica Editora, 2011.

- RUBIO, David Sánchez. Fazendo e desfazendo Direitos Humanos. Santa Cruz do Sul: EDUNISC, 2010.

- SANTOS, Boaventura de Sousa. Um discurso sobre as Ciências. 7ª ed. Porto: Afrontamento, 1995.

\footnotetext{
${ }^{15}$ LYRA FILHO, Roberto. "Desordem e processo: Um posfácio explicativo". In: LYRA, Deodoró Araujo (Org.). Desordem e processo: estudos sobre o Direito em homenagem a Roberto Lyra Filho, na ocasião do seu $60^{\circ}$ aniversário. Porto Alegre: Sergio Antonio Fabris Editor, 1986, p. 295.
} 